\title{
Jóvenes y participación política en el oriente colombiano: el papel de las redes sociales y los medios masivos
}

Youth and political participation in Colombia's east: the role of social networks and the mass media

Jovens e participacao política no oriente colombiano:

o papel das redes sociais e os meios massivos de comunicação

Jeunes et participation politique dans l'est colombien: le rôle des réseaux sociaux et des medias de communication de masse

\section{Giovanni Bohórquez Pereira}

Magister en Ciencias Políticas

Miembro del grupo de investigación TIC y Ciudadanía Universidad Pontificia Bolivariana, Bucaramanga - Colombia

Correo electrónico: giovanni.bohorquez@upb.edu.co

\section{Olga Beatriz Rueda Barrios}

Doctora en Contenidos de Comunicación Digital

Miembro del Grupo de Investigación Comunicación, Cultura y Desarrollo Universidad Pontificia Bolivariana, Bucaramanga - Colombia

Correo electrónico: olgab.rueda@upb.edu.co

Cómo citar este artículo:

Bohórquez, G. y Rueda, O. (2019). Jóvenes y participación política en el oriente colombiano: el papel de las redes sociales y los medios masivos. Revista de la Facultad de Derecho y Ciencias Políticas, 49 (130),pp. 175-201. doi: http://dx.doi.org/10.18566/rfdcp.v49n130.a08

Recibido: 17 de diciembre de 2018.

Aprobado: 28 de mayo de 2019. 


\section{Resumen}

La investigación profundiza en los mecanismos de participación política a los que jóvenes del oriente colombiano recurren con mayor frecuencia, así como también en el uso y apropiación de las redes sociales digitales. De igual forma, el artículo versa sobre los medios masivos de mayor consumo e incidencia para decisiones de tipo político y electoral en el país, y sobre los condicionantes sociales que intervienen en ellas. La metodología se desarrolló bajo un enfoque mixto, con prevalencia de lo cualitativo, y con una muestra de tipología "típica o intensiva" de carácter no probabilístico bajo criterios de selección. Se destacó que los jóvenes usan y se apropian las redes sociales para fines de relacionamiento y, a través de ellas y de los medios tradicionales, se informan sobre la agenda pública. Entre las conclusiones vale resaltar que los jóvenes del oriente colombiano realizan procesos de multi-comunicacionalidad, con interacción permanente en más de una dirección y con diversas personas.

\section{Palabras clave}

Jóvenes, incidencia, participación política y electoral, redes sociales y medios masivos.

\section{Abstract}

The investigation focuses on the political participation mechanisms that young people from Colombia's east tend to use more often and, also, on the usage and appropriation of the digital social networks. Likewise, this paper refers to the mass media with the highest consumption and incidence in political and electoral decisions, as well as to the social conditioning factors that intervene in them. The methodology was carried out under a mixed focus, with qualitative prevalence, and with a sample of "typical or intensive" typology of a probabilistic nature under selection criteria. It was highlighted that young people use and appropriate social networks aiming to socialize and, through them and traditional media, they inform themselves about the public agenda. Among the conclusions, it is worth noting that young people from Colombia's east perform multi-communication processes, with a permanent interaction in more than one direction and with diverse individuals.

\section{Key Words}

Youth; Incidence; Political and electoral participation; Social networks and mass media.

\section{Resumo}

Essa pesquisa examina os mecanismos de participação política usados mais frequentemente pelos jovens do oriente colombiano, da mesma forma, o uso e apropriação das redes sociais digitais. Igualmente, esse artigo trata os meios massivos de comunicação de maior consumo 
e incidência para as decisões politicas ou eleitorais no país, além disso, os condicionantes sociais que intervêm nelas. A metodologia consiste numa abordagem mista com prevalência do qualitativo e uma amostragem de tipologia "típica ou intensiva" de caráter não probabilístico sob critérios de seleção. Salientou-se que os jovens usam e se apropriam as redes sociais para fins de relacionamento, através delas e dos meios tradicionais eles se informam sobre a agenda pública. Entre as conclusões é importante destacar que os jovens do oriente colombiano realizam processos de comunicação múltipla, com interação permanente em mais de uma direção e com diversas pessoas.

\section{Palavras-chave}

Jovens, incidência, participação política e eleitoral, redes sociais e meios massivos de comunicação.

\section{Résumé}

L'enquête approfondit les mécanismes de participation politique auxquels recourent le plus fréquemment les jeunes de l'est colombien, ainsi que leur usage et appropriation des réseaux sociaux digitaux. De la même manière, l'article traite des medias de communication de masse beaucoup consommés et ayant une grande incidence sur les décisions de type politique et électoral dans le pays et des facteurs de conditionnements sociaux qui interviennent dans cellesci. La méthodologie se développe selon une approche mixte, avec la prévalence du qualitatif et une démonstration de typologie "typique ou intensive » de nature non probabiliste selon les critères de sélection. Il ressort que les jeunes utilisent et s'approprient les réseaux sociaux à des fins relationnelles et, à travers de ceux-ci et des medias traditionnels, ils s'informent de l'agenda public. Dans les conclusions il est important de souligner que les jeunes de l'est colombien réalisent des processus de multi-communication avec des interactions permanentes dans plus d'une direction et avec différentes personnes.

\section{Mots clés}

Jeunes, incidences, participation politique et électoral, réseaux sociaux et medias de communication de masse.

\section{Introducción}

El escenario de la globalidad se caracteriza por el uso y aprovechamiento de las tecnologías de información y comunicación (TIC), y en este se evidencian cambios en las tácticas de relación y en las nuevas formas de poder. En este 
sentido, diversos casos dan cuenta del impulso de las redes sociales para incidir en las decisiones de carácter electoral en diferentes países del mundo, entre ellos, el de Barack Obama en su reto por alcanzar la presidencia de los Estados Unidos; o las acciones de movilidad ciudadana convocadas desde Facebook o Twitter, las cuales han logrado aumentar la visibilidad y modificar la agenda pública, donde la Primavera Árabe, el 15M, por ejemplo, fungen como casos de éxito.

En este sentido, se destaca el uso del escenario digital para promover acciones políticas y su relación con la generación de nuevos espacios para el debate y la confrontación de ideas, tal como lo afirma Caldevilla (2009):

De su impacto más profundo en política solo estamos ante la punta del iceberg: nuevas formas de movilización, liderazgo y retórica; nuevas formas de planteamiento en las campañas electorales; un lugar diferente y nuevas obligaciones para los partidos políticos. Por encima, podemos decir que estamos ante una nueva forma de hacer y pensar la política, que entiende la importancia de la conversación e interacción social (sic) y el cambio cultural hacia el soporte virtual como quehaceres al menos tan importantes como el ejercicio de la administración. (Caldevilla, 2009, p. 35)

Desde esta perspectiva, los usos de las redes sociales pueden apreciarse como una oportunidad para lograr procesos democráticos, y también como un canal difusor de ideas y productos de consumo, lo cual deviene en fronteras difusas entre la publicidad, el marketing y la democracia 2.0.

Según el Ministerio de Tecnologías de Información y Comunicación en Colombia (2015), en los últimos años este país ha registrado un crecimiento exponencial en cuanto a la cantidad de usuarios que se encuentran registrados en las redes sociales, especialmente, uno de los segmentos poblacionales con mayor crecimiento en el uso de los contenidos que circulan en las redes son los jóvenes.

Redes como Facebook y Twitter son las que gozan de mayor popularidad entre los colombianos, a tal punto que, en Facebook, Colombia ocupa el lugar número 14 en el contexto internacional, con más de 15 millones de usuarios, mientras que Bogotá es la novena ciudad del mundo, con una cifra cercana a los 6.5 millones de consumidores registrados en estas plataformas. 
En el caso de Twitter, según el estudio Uso y apropiación de las TIC en Colombia, publicado en 2015, el $29.3 \%$ de los colombianos pertenece a esta red, cifra relevante si se tiene en cuenta que el número estimado de usuarios ha ido en aumento además de las características del medio que se ha convertido en el canal predilecto por medios de comunicación, campañas políticas, deportistas, personajes de gobierno, entre otros. Estas cifras sitúan a Colombia, en cuanto al número de usuarios de Twitter, por encima países como Francia y Alemania.

Ahora bien, en el campo de lo electoral, la Misión de Observación Electoral, MOE (2011), asegura que los jóvenes de Colombia deciden su voto desde tres grandes ámbitos: propuestas de candidatos $(87,6 \%)$, trayectorias académica y laboral del candidato (86 \%) y lo recibido por los medios masivos $(69,9 \%)$. Este último dato confirma la presencia de los medios masivos en las decisiones de orden político electoral.

Tabla 1. Decisiones de voto según encuesta DANE 2013-2015

\begin{tabular}{lll}
\hline \multicolumn{3}{c}{ ¿Cuándo hay elecciones en Colombia, usted? } \\
\hline AÑO 2013 & TOTAL PERSONAS & $\mathbf{1 8 ~ A ~} 25$ AÑOS \\
\hline ENCUESTADOS & $24247(100 \%)$ & $4706(19,4 \%)$ \\
\hline SIEMPRE VOTA & $\mathbf{1 3 0 6 6}(\mathbf{5 3 , 9} \%)$ & $\mathbf{1 4 7 8}(\mathbf{3 1 , 4} \%)$ \\
\hline AVECES VOTA & $\mathbf{6 0 6 4 ( 2 5 \% )}$ & $\mathbf{8 0 1 ( 1 7 \% )}$ \\
\hline NUNCA VOTA & $\mathbf{5 1 1 7}(\mathbf{2 1 , 1} \%)$ & $\mathbf{2 4 2 7}(\mathbf{5 1 , 6} \%)$ \\
\hline AÑO 2015 & TOTAL PERSONAS & $\mathbf{1 8 ~ A ~ 2 5 ~ A N ̃ O S ~}$ \\
\hline ENCUESTADOS & $\mathbf{2 5 2 1 9}(100 \%)$ & $\mathbf{4 8 5 8}(\mathbf{1 9 , 3} \%)$ \\
\hline SIEMPRE VOTA & $\mathbf{1 5 1 0 5}(\mathbf{5 9 , 9} \%)$ & $\mathbf{1 8 5 4}(\mathbf{3 8 , 2} \%)$ \\
\hline AVECES VOTA & $\mathbf{5 8 9 4}(\mathbf{2 3 , 4} \%)$ & $\mathbf{9 9 7}(\mathbf{2 0 , 5} \%)$ \\
\hline NUNCA VOTA & $\mathbf{4 2 2 0}(\mathbf{1 6} \%)$ & $\mathbf{2 . 0 0 8 ~ ( 4 1 , 3 \% )}$ \\
\hline Fuente: elaboración propia, datos encuesta DANE 2013-2015.
\end{tabular}

En el año 2017, la Registraduría Nacional del Estado Civil informó que, del total de la población apta para votar en Colombia, 16 \% era joven (18 a 26 
años) y solo el $10 \%$ de ella vota, efectivamente. En cifras, esto significa que, de los 27 millones de ciudadanos aptos para votar, 7 millones eran jóvenes y, de ellos, acudieron a las urnas solo 700 mil.

Desde esta perspectiva se coligen diversos aspectos importantes para el análisis de la incidencia de las redes sociales y los medios masivos en la participación política y electoral de los jóvenes: ¿las juventudes colombianas son apáticas a participar en actividades políticas y electorales?, ¿la decisión de voto sigue siendo una tradición política de familia que no ha logrado desarraigarse en la población joven?, ¿cuáles son las redes sociales y medios masivos de mayor uso y apropiación de los jóvenes en Colombia?, y, finalmente, ¿cuál es la incidencia del uso de las redes sociales y los medios masivos en la participación política y electoral de los jóvenes?

A continuación, se desarrollarán los aspectos teóricos y metodológicos que orientaron este estudio.

\section{Ubicación teórica de la investigación}

Las ciencias políticas, la psicología, la sociología política, la antropología social y, en menor escala, la comunicación social, son disciplinas desde las cuales se han realizado investigaciones sobre los jóvenes y el comportamiento político. Botero y Torres (2008) registran con precisión los cuatros campos desde donde se han estudiado, en diferentes tiempos y contextos, las dinámicas juveniles en este aspecto.

La primera línea de investigación posa su mirada en la medición de la conducta del joven y su voto; sus comportamientos y actitudes en las campañas. De igual manera, analiza los procesos formales de la política de los jóvenes, disposición para cargos públicos, abstencionismo y animadversión a los sistemas políticos, basado en la crisis de legitimidad del sistema político en general.

La participación juvenil se analiza por la variable demográfica de la edad, la cual sostiene una tesis clásica que apunta a la existencia de un vínculo estrecho entre juventud y participación política no convencional. Sin embargo, la incidencia de la edad se ve mediatizada por otras circunstancias que responden a los procesos culturales y al contexto socio político de la época. (Botero \& Torres, 2008, p. 583) 
Sin embargo, señalan los autores (2008) que esta línea teórica tiene limitaciones al considerar la participación como una conducta que se mide y controla, excluyéndolo que obvia o excluye otros modelos de participación, así como la época histórica, los modos y los lugares donde se realiza esta actividad. De esta manera, la participación como acción política, más que una conducta externa que permita el control de variables de manera intencional, es un proceso por medio del cual los jóvenes inciden y autodeterminan su existencia en relación con las condiciones de vida.

Los estudios referentes a este tema se centran en la medición de la conducta de voto a través de indicadores, tales como la asistencia a mítines, el apoyo económico a una campaña, el trabajo para algún partido y el ejercicio de la persuasión para que otros individuos voten por un candidato determinado.

La integración del sujeto a luchar por causas sociales o a grupos determinados es el interés principal del segundo campo de investigación en jóvenes. En este sentido, los individuos en sociedad hacen parte de diversos colectivos o agrupaciones y cada uno de ellos les genera filiación e identidad.

Hay identidades basadas en características biológicas, demográficas o culturales (sexo, edad, lengua, acervo cultural común, color de la piel, grupos étnicos), identidades sociales basadas en la ocupación profesional con diversos grados de inclusividad, asociación profesional o sindical, 0 las que se basan en identificaciones de clases sociales. (Botero \& Torres, 2008, p.585)

Situaciones como la exclusión, la discriminación, la frustración y el descontento hacen que las personas se encuentren, se agrupen y se identifiquen, y a partir de estos escenarios y realidades que los unen, los individuos organizan grupos que tienen acciones sociales y políticas para influir en determinados contextos.

Una de las complejidades de la investigación en el campo de la política en relación con los jóvenes es la identificación de las temáticas de interés para este grupo poblacional, en tanto las discusiones e inquietudes de los jóvenes han dejado ser locales, para convertirse en globales, dadas las posibilidades de Internet. Es decir, algunos de los temas que los inquietan los llevan a buscar afinidades a través de la virtualidad, por lo cual se adhieren a causas mundiales, y así participan y deliberan en escenarios como las redes sociales; en este sentido, las problemáticas locales y la participación política en escenarios virtuales no tienen fronteras y agudizan el sentido de identificación. 
La siguiente línea investigativa hace referencia a la participación juvenil como derecho, construcción de política pública y propuesta de formación. Vista desde estos ámbitos, la investigación tiene como prioridad estudiar la incidencia de los jóvenes en los procesos relacionados con lo público y su efectiva acción en la formación para el ejercicio y exigencia de los derechos; por consiguiente, se indaga por acciones de promoción de los derechos sociales y políticos, experiencias significativas y reales de participación orientadas al fortalecimiento de capacidades ciudadanas y visibilización de materiales producidos con fines educativos, tales como manuales o libros. De manera que es significativa la intención de fomentar la construcción de hábitos relacionados con la cultura política a fin de promover consciencia en torno a la participación social desde variables como manejo de la información, la capacidad de decisión, los grados de compromiso y empoderamiento.

Finalmente, la cuarta línea le apunta a las variaciones en los contextos políticos y culturales como escenarios de socialización de participación activa.

Por otra parte, se puede señalar que América Latina, entre los siglos XX y XXI, ha entregado aportes significativos a las lecturas hermenéuticas sobre jóvenes y participación política. Investigadores como Rivera-González (2013), Patricio Rivas (2010), Arturo Guerrero (2010), Ana Rosas Mantecón (2002), Rossana Reguillo (2000), Pérez Islas (1998), Manuel Valenzuela (1998), Jesús Martín-Barbero (1994), Néstor García-Canclini (1999), entre otros, hacen parte del destacado grupo de estudiosos sobre la temática de los jóvenes en la sociedad actual y su accionar político. Las limitadas oportunidades a las que tienen acceso, los estereotipos y estigmatizaciones con que se les marca socialmente, el desconocimiento y la poca valoración de sus capacidades para generar ideas y expresiones culturales desde sus entornos y condiciones son, entre otras, las denuncias y reclamos que los teóricos de este lado de América hacen de manera constante.

Para el caso particular de Colombia, Quintero (2005) registra cómo a partir de los años cincuenta y de las décadas siguientes, el país entra en la dinámica de productividad económica a fin de acercarse, o pretender alcanzar, parámetros de crecimiento internacional, y para ello hace cambios que impactan su composición demográfica, política y social.

Migración a la ciudad, industrialización y los nuevos roles que asume la familia en el contexto urbano son algunas de las características de esta nueva sociedad, donde los adolescentes apropian comportamientos y actitudes 
que transforman lo tradicional. De esta manera, durante 40 años, hombres y mujeres jóvenes insertados en la urbe incursionan en la fuerza laboral, con pequeñas o nulas oportunidades de estudio e inmersos en la dinámica propia del mercado. Al mismo tiempo, en esas mismas ciudades, se encuentran jóvenes con otras condiciones de vida y miradas sobre su realidad; esas tipologías, desde sus respectivos escenarios, ampliaron la brecha social. Por otra parte, la incrustación en Colombia del narcotráfico y el incremento del conflicto armado interno son condicionantes sociales que activaron, en algunos casos, la participación política, como lo ejemplifica el movimiento juvenil que se gestó desde las universidades públicas para luchar por mejores condiciones de vida, no solo para los jóvenes, sino para la población en general.

Quintero (2005, p. 98) registra cómo la década de los noventa ofreció un ambiente reformista político y social debido al proceso de creación de la Asamblea Nacional Constituyente, que, a su vez, dio origen a la Constitución de 1991. No obstante, el conflicto social no fue superado, esto se ve reflejado en la leve disminución de la pobreza, en el estancamiento del mejoramiento de las condiciones de vida, en la caída del ingreso real, en el crecimiento de la informalidad y el desempleo en los adultos jóvenes, así como en el incremento de la violencia y la delincuencia urbanas y en el aumento en las tasas de fecundidad y de la deserción escolar.

Posteriormente, en 1997, se promulga la ley de la juventud, la cual, además de reconocer la existencia de los jóvenes como sujetos sociales, les otorga el ejercicio pleno y solidario como ciudadanos responsables y transformadores del entorno. Sin embargo, estas intenciones debieron caminar de la mano con el neoliberalismo, un modelo económico no propiamente social y equitativo, en el que los jóvenes son considerados como potenciales clientes y desde el cual se orientan estrategias publicitarias para cautivarlos para servir a sus fines.

Aunque en la actualidad prevalezca la intención de parte de múltiples entidades y de los mismos jóvenes a través de grupos, colectivos o movimientos juveniles, de buscar espacios diferenciadores y contestatarios, por medio de múltiples formas, medios y lenguajes de expresión, esto no ha bastado para romper los hilos que dominan lo económico e imponen la hegemonía social. "Estos lenguajes de los/las jóvenes (verbales, gestuales, visuales, grafológicos, etc.) conducen, tal vez, a apostarle a ese nuevo paradigma en el cual existen 'nuevas maneras de pensar sobre nosotros mismos, nuestra relación mutua y la sociedad en la que vivimos' (Barnett citado en Escobar, 2009, p.115). 
Ahora bien, referirse a las dinámicas sociopolíticas del país, especialmente cuando se trata de indagar sobre el comportamiento de los jóvenes y su participación política en un escenario de globalidad y uso de redes sociales como espacio para la interacción pública, implica la caracterización de estos actores y la determinación de los poderes para apoyar, resistir o ser ajenos a las situaciones de la agenda pública nacional.

Los fenómenos sociopolíticos y de gobierno, según Kooiman (2003), deben estar situados en un contexto sistémico que se caracteriza por: 1) multiplicidad de actores, sus objetivos, intenciones y poderes; 2 ) complejidad de las estructuras y relaciones en los diversos niveles que hacen parte del sistema; y 3) la dinámica de las tensiones en un sistema y entre sistemas. Estos elementos establecen oportunidades (la forma en que estas son creadas y empleadas) y problemas (la manera en que son formulados y resueltos). (Castillo, 2017, p. 168)

A continuación, se enuncian los elementos metodológicos que orientaron el proceso de análisis.

\section{Metodología}

La investigación correspondió al paradigma cualitativo, en tanto propició acercamientos y consultas sobre participación política y electoral de los jóvenes en la región del oriente colombiano entre 2017 y 2018. Su tipología fue explicativa, al ahondar en las causas de los eventos y fenómenos físicos sociales.

De otro lado, el enfoque del proyecto se enmarca en el modelo de macromolde hermenéutico (Losada \& Casas, 2010) que centra su atención en llegar a la comprensión profundidad de

los fenómenos, entendida no en términos de empatía o de actitud tolerantes, sino de comprender el significado de las acciones desde el punto de vista de quién las lleva a cabo, habida cuenta del contexto dentro del cual tienen lugar y en cuanto condicionadas por este. (p. 53)

El macromolde hermenéutico tiene su base epistemológica en la ciencia política, a partir de Donald Campbell y Julián Stanley (1966) y de la Escuela de Chicago, con sus representantes Harold Gosnell y Harold D. Lasswel. 
La investigación privilegió el modo dialógico; por consiguiente, se acudió a las creencias, los sentimientos y percepciones como puntos fundamentales para profundizar acerca de la realidad humana que se quería analizar.

Así, se definieron técnicas de recolección de información como la encuesta, la entrevista a profundidad y los grupos focales. Entre los ejes temáticos desarrollados se destacan aspectos de orden sociodemográfico, hábitos de uso y apropiación de los medios masivos y redes sociales, y condicionantes políticos de primer y segundo orden para las decisiones de políticas y electorales de los jóvenes.

La muestra utilizada corresponde a muestras típicas o intensivas, toda vez que se consideró que con ellas se lograban pautas establecidas en la investigación. En primer lugar, una población homogénea en edad y con actividades o roles sociales similares. Al mismo tiempo, cada grupo poblacional, dependiendo del lugar de procedencia, representaba aspectos propios de su cultura; es decir, de Norte de Santander, con Cúcuta y Ocaña; de Santander, con Barrancabermeja, San Gil y Bucaramanga.

De igual manera, con la muestra se buscó confirmar diferencias reales 0 sustanciales en lo referente a condiciones de acceso a medios y la presencia e incidencia de sus valores políticos de primer y segundo orden en lo político y electoral.

En consecuencia, la muestra, que más allá de obedecer a un criterio de representatividad, se ciñe al principio de saturación de la información, tal como se establece para los estudios de tipo cualitativo, se configuró con 25 jóvenes, cinco por cada municipio, para la aplicación del formato de entrevista; además, se convocaron a siete jóvenes para cada grupo focal. Se aplicaron dos entrevistas más por cada municipio, a manera de prueba, y un grupo focal, que sirvió para verificar y ajustar instrumentos.

Finalmente, el diseño que se eligió fue el multietápico, y se contemplaron cuatro momentos: primero, la exploración conceptual; segundo, el diseño de los instrumentos, trabajo de campo y sistematización. La tercera fase fue el análisis de los datos y, finalmente, las conclusiones del estudio. 


\section{Resultados}

\section{Contexto y mecanismos de participación política}

El oriente colombiano refleja las condiciones sociopolíticas que caracterizan el país, es decir, desigualdad en las riquezas, oportunidades y limitaciones, producto de inequidad, indiferencia del Estado y de las huellas del conflicto armado interno en el que confluyeron las guerrillas y los paramilitares por más de cinco décadas, características que dejaron a su paso pobreza, problemas de narcotráfico, desaparición forzada, migrantes internos, bandas urbanas criminales, entro otras situaciones de complejidad.

La región se reconoce por su potencial para la extracción minera, para la cerámica, la industria del calzado y la ropa infantil. La frontera con Venezuela es de 700 kilómetros y sus expresiones culturales e históricas hacen que esta zona se caracterice por su jerarquía y la forma directa de afrontar sus dificultades. Sin embargo, los ejercicios democráticos relacionados con sus gobernantes departamentales y locales han sido fallidos. En la última década, más de tres alcaldes de la zona y un número que supera los diez concejales han sido destituidos por deficientes manejos de los dineros públicos.

La población de los dos departamentos, según el Departamento Nacional de Estadística, DANE (2017), supera los tres millones 460 mil habitantes, que representan el 7,36 \% de la población de Colombia, y el potencial electoral para los comicios de octubre de 2016 (plebiscito para refrendar acuerdos de paz) fue de dos millones 782867 ciudadanos aptos para votar. La abstención en promedio de los dos departamentos o provincias fue del $58 \%$ (Santander $56,32 \%$, Norte, $59,69 \%$ ) (ver figura 1 ).

Figura 1. Mapa de Colombia y zonas del estudio.

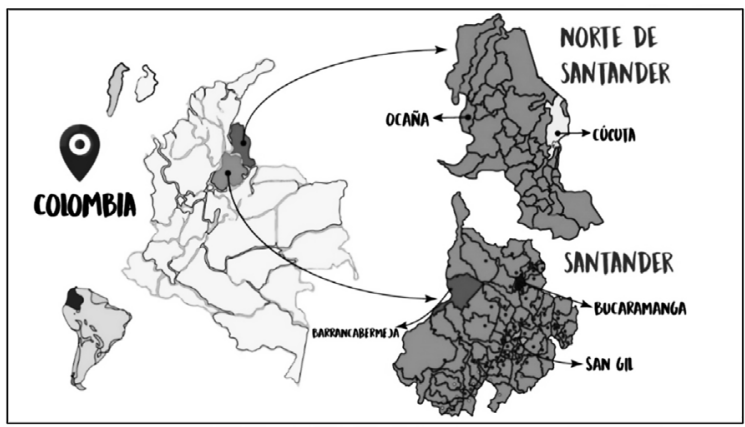

Fuente: elaboración propia 
Los jóvenes consultados corresponden, en un $53 \%$ a hombres, y en un $47 \%$ a mujeres. De ellos, un 72 \% manifestó que vivía con su grupo familiar primario, es decir, prevalece el modelo de familia tradicional (mamá, papá y hermanos). La ocupación de los jóvenes se concentra particularmente en estudios universitarios.

Tabla 2. Población consulta en el proyecto

\begin{tabular}{|c|c|c|c|c|c|}
\hline \multirow{2}{*}{$\begin{array}{l}\text { ZONA } \\
\text { NORTE DE SANTANDER }\end{array}$} & \multicolumn{2}{|c|}{ GÉNERO } & \multicolumn{2}{|c|}{$\begin{array}{l}\text { TÉCNICA DE } \\
\text { RECOLECCIÓN }\end{array}$} & \multirow[t]{3}{*}{ TOTAL } \\
\hline & \multirow[t]{2}{*}{ HOMBRE } & \multirow[t]{2}{*}{ MUJER } & \multirow[t]{2}{*}{ ENTREVISTA } & \multirow{2}{*}{$\begin{array}{l}\text { GRUPO } \\
\text { FOCAL }\end{array}$} & \\
\hline & & & & & \\
\hline CÚCUTA & 7 & 7 & 7 & 7 & 14 \\
\hline OCAÑA & 10 & 10 & 9 & 11 & 20 \\
\hline SUBTOTAL & 17 & 17 & 16 & 18 & 34 \\
\hline \multicolumn{6}{|l|}{ SANTANDER } \\
\hline BUCARAMANGA & 13 & 5 & 9 & 9 & 18 \\
\hline BARRANCABERMEJA & 5 & 9 & 7 & 7 & 14 \\
\hline SAN GIL & 7 & 7 & 7 & 7 & 14 \\
\hline SUBTOTAL & 25 & 21 & 23 & 23 & 46 \\
\hline TOTAL & 42 & 38 & 39 & 41 & 80 \\
\hline
\end{tabular}

Fuente: elaboración propia.

Para esta investigación fue relevante conocer el comportamiento de la participación electoral de los jóvenes. De ellos, el 42 \% ha votado en tres comicios electorales; el 17\% ha ido a las urnas al menos una vez, y el otro 41 $\%$ nunca ha ejercido el derecho al voto.

Los jóvenes manifestaron que su participación en las votaciones ha sido para elegir gobernadores, alcaldes, diputados, concejeros municipales, congresistas y presidente de la República. Además, un 10 \% manifestó haber votado en procesos de revocatoria de mandato en sus municipios de origen.

Los jóvenes expresaron conocer los mecanismos de participación política. El $100 \%$ de los encuestados coincidió en que el voto popular es el más conocido; el 64 \% manifestó conocer otras herramientas, como el plebiscito y la revocatoria del mandato. De igual forma, reconocen otras acciones, como la 
rendición de cuentas (23\%), las veedurías ciudadanas (18 \%), la participación en partidos políticos (79 \%) e, incluso, los mecanismos para la exigencia de derechos fundamentales, como la tutela (86 \%). Sobre estos mecanismos ellos afirman que los identifican como figuras de participación política que les permiten incidir en los asuntos públicos.

De los jóvenes consultados a través de las entrevistas, más de la mitad afirmaron que el voto no es el único medio para participar políticamente, pero lo catalogaron como el más efectivo:

Participación política no es simplemente el hecho de salir el día de las elecciones a votar, también es tratar de instaurar una postura política de tratar de debatir con las personas más cercanas, tratar de llevar ese debate a otros con el simple hecho de debatir, para que exista una verdadera democracia, una verdadera contienda de ideas y se pueda hablar de política sanamente en Colombia. (Estudiante de 21 años de Bucaramanga, entrevista, 10 de junio de 2017).

En cuanto a la definición sobre participación política, la mayoría coincide en afirmar que es una manera de hacerse presentes y de discutir los ejercicios de poder en la sociedad. En ese sentido, algunos de ellos reconocen que, para participar políticamente, se debe ser un "ciudadano activo", y que es desde la inconformidad donde se incita a concurrir a los mecanismos de participación electoral.

Ese término no es solamente para los que están en el congreso, ese término abarca a los ciudadanos en general, cuando hablo de participación política es de cómo yo influyo en la toma de decisiones, de mi ciudad, a nivel nacional, como apoyo una iniciativa, la participación se da en diferentes espacios, cuando salgo a votar, cuando nos sentamos a construir planes de desarrollo, cuando vamos a una sesión del consejo, eso es participación política, cuando organizo un grupo de jóvenes y les explico que es liderazgo, eso es participación política. (Estudiante de 23 años de Barrancabermeja, 17 de junio de 2017).

Finalmente, los jóvenes admiten que existe una carencia de información y formación en el uso y la importancia de los mecanismos de participación democrática y electoral, y reconocen que la desinformación alimenta su apatía política. "Debemos informarnos, porque no podemos esperar que vengan a hacerlo", así lo expresa una de las personas entrevistadas en esta investigación. 
Pero ahí insisto, ¿por qué no salimos a votar? Por falta de conocimiento. Tú hablas con la gente y les dices "vamos a votar" y responden: "Ay, eso para qué, eso es lo mismo, todos dicen cosas bonitas, se suben al poder no cumplen nada”. Entonces es complicado. (Estudiante de 22 años de Ocaña, 1 de julio de 2017).

\section{Uso y apropiación de las redes sociales}

En esta materia, los jóvenes, en un 100 \%, reconocieron estar vinculados a plataformas virtuales y hacer uso continuo de ellas. En cuanto a preferencia en uso de redes sociales, el 90 \% manifestó su predilección por Facebook; en segundo lugar, con 42 \%, Instagram; en tercera posición, con un $23 \%$. En cuarto lugar, de importancia está, con un11\%, YouTube (Ver figura 3).

Figura 2. Redes sociales de mayor acceso por parte de los jóvenes del estudio.

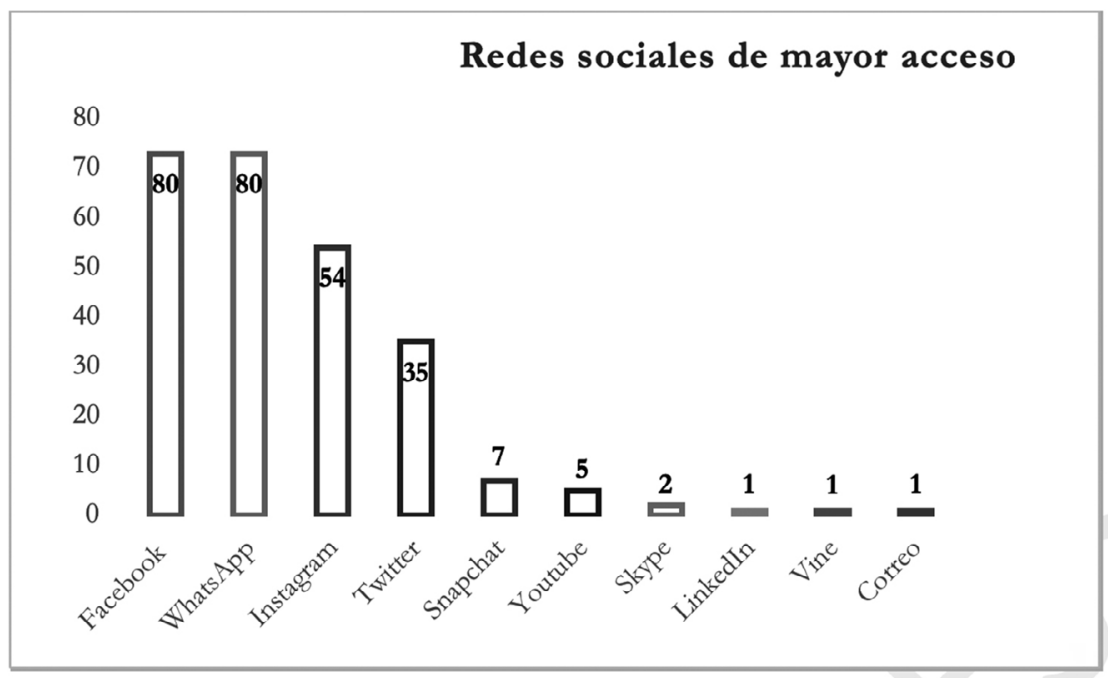

Fuente: elaboración propia.

En lo relacionado con la preferencia de medios masivos, la televisión fue el canal de mayor aceptación, con $84 \%$ de favorabilidad, seguido por la radio, con un $11 \%$, y por la prensa escrita, con un $5 \%$.

Los jóvenes manifiestan que tener cuenta en Facebook es un "requisito social", en tanto, se ha convertido en una red que contiene funciones propias de otras aplicaciones que les permiten socializar, compartir información, publicar 
imágenes y videos y seguir a otros. No obstante, expresan que WhatsApp es considerada como la aplicación de mensajería más importante para ellos, está presente en su rutina diaria y ha logrado hacerlos migrar de Facebook, ya que les permite tener respuesta de manera instantánea de las personas con las que se relacionan.

Por su parte, Instagram fue la segunda red social más reconocida por los jóvenes. En las entrevistas reseñaron que su uso es para fines de entretenimiento y ocio, especialmente, para generar su propia identidad a través de imágenes y seguir a otros. De esta red social destacan que no reciben contenido político.

Finalmente, Twitter fue identificada como la red social de mayor contenido político, las narrativas y los formatos a través de los cuales se evidencia este contenido son imágenes, gifs, textos, videos y memes. Los jóvenes reconocen en Twitter un escenario para el debate político en el que identifican perfiles de influenciadores en diversos temas. En este contexto, expresiones como "la gente piensa que soy lista, pero realmente soy un banco de tweets" tienen cabida dentro de su grupo de usuarios.

Al preguntarles cada cuanto revisan sus redes sociales, los jóvenes dijeron que cada 5 o 10 minutos ingresan a sus móviles en busca de novedades; esta situación hace que la información se reciba en tiempo real y que lo publicado en pocas horas se reoriente 0 cambie de acuerdo con la situación difundida, la fotografía expuesta o el pronunciamiento de un líder político, deportista, cantante o personaje público, aspecto que se incrementa o reduce en relación con el impacto o seguidores que tenga.

[...]ahora es muy fácil tener un celular, un computador, un televisor en todas las casas, en la mayoría, entonces los niños ahora los mueven ya que son nativos digitales son expertos en el tema eso se le facilita mucho y pues tienen mucho tiempo libre y si podrían llegar a las ocho horas diarias. (Estudiante de 22 años de Bucaramanga, 10 de junio de 2017).

Ahora bien, los contenidos que más consumen, comentan y comparten los jóvenes son noticias, fotos, memes, videos y publicidad sobre ropa; en general, los temas atienden a asuntos políticos y ambientales; un formato que les interesa fuertemente son los influenciadores o youtubers, los cuales, en su gran mayoría, dicen, son replicados o remitidos por sus amigos y familiares. "Lo leo, lo priorizo, si es una noticia profundizo, depurar la información que es importante para mí” Comenta una de las estudiantes entrevistadas. 
En mis redes sociales llega de todo, actualidad política y relacionado con la Alcaldía de Bucaramanga, también me llega contenido de lo que sigo depende mucho de las páginas que uno siga ejemplo, medios de comunicación, Fan-page de la alcaldía, colectivos, grupos de música, depende del tema lo abro, lo leo y si tengo la necesidad de compartirlo para que alguien más lo lea, lo hago porque yo pertenezco a un grupo donde nos compartimos información. (Estudiante de 22 años de Bucaramanga, 10 de junio de 2017).

Los jóvenes en Colombia realizan ejercicios de clasificación y categorización de la información recibida y en fracciones de segundo aprueban, eliminan y comparten contenidos en sus redes sociales. Precisamente sobre qué y a quién compartir, lo asumen como una actividad espontánea. Expresan que el contenido político es limitado, pero, en ocasiones, este se comparte más como respuesta a lo remitido por un conocido o amigo, que como una iniciativa de hacer visible su pensamiento.

El ejercicio de comentar las publicaciones no es una práctica frecuente entre los jóvenes participantes del estudio, sin embargo, cuando lo hacen, los comentarios giran en torno a temas sociales polémicos y de sus propios intereses, en ocasiones establecidos por contenido viral o por las tendencias de la Web.

El WhatsApp para comunicarnos, aunque ahora están pasando las cadenas, la información que pasan por los chats. En Facebook casi no interactúo, pero sí para informarme, pero no tanto para interactuar. Instagram también para subir cosas, Twitter para informarme y chatear, porque ahora se puede en todas las redes. (Estudiante de 21 años de San Gil, 3 de junio de 2017).

Una tendencia que se registra es la actitud de prevención y rechazo a la "invasión" de los adultos (padres y familiares) a los espacios o lugares virtuales que ellos consideran como propios. Los jóvenes coincidieron en señalar que la llegada de los adultos a las redes es una "intromisión" y que los ha llevado a tomar posiciones al respecto, entre ellas, retirarse de algunas redes o migrar hacia otras menos conocidas por los padres. No obstante, la interacción de contenidos entre amigos, conocidos y familiares evidenció reflexiones de los jóvenes sobre lo que está ocurriendo con la dinámica social, en particular, en la relación con los más cercanos: la familia. Si bien reconocen ventajas y desventajas del uso de las redes como vínculo de conexión con cercanos y desconocidos, también admiten que ha logrado que los integrantes del hogar intercambien mensajes, con propósitos diversos como fortalecimiento de vínculos, vigilancia o apoyo en momentos particulares. 
Yo me he privado de compartir cosas en mis redes sociales, porque hasta mi mamá tiene Facebook...A mí me pasó que un tío me bloqueó... lo que pasa es que publico muchas cosas de política y básicamente él es muy religioso, entonces, por eso me bloqueó. (Estudiante de 22 años de Bucaramanga, 10 de junio de 2017).

Otra de las personas que hicieron parte de este sondeo comenta:

A mí me parece que la red social ha unido al mundo de una manera nunca antes vista, la Internet ha sido uno de los grandes logros de la humanidad; en ese sentido, ha permitido la inmediatez y la unión; por ejemplo, una persona en Japón puede entender la idiosincrasia colombiana. (Estudiante de 23 años de Bucaramanga, 10 de junio de 2017).

Por otra parte, los jóvenes son también consumidores de los medios de comunicación tradicionales y procuran contrastar la información política que se publica en ellos, con lo que circula en las redes sociales.

Durante las entrevistas y los grupos focales, ellos afirmaron que el contenido político que reciben proviene de los noticieros de los canales privados de televisión y los ven especialmente en las mañanas, mientras se organizan para salir de casa. Reconocen la presencia de la radio, por lo general, la escuchan en el transporte público al ir al trabajo o al lugar de estudio. De igual forma, dicen leer la prensa de vez en cuando, pero es más frecuente su consulta a través de los portales Web en Internet.

Consideran que los medios masivos no son fuentes idóneas para informarse políticamente, en tanto opinan y son manipuladores dados los intereses económicos y políticos que los configuran.

Yo siempre he considerado los medios masivos un poco manipuladores, hay que mirar allí y allá para poder tener una verdad, porque son muy manipulables; yo creo que los medios están bien, como tres años por lo mismo, las noticias siempre son desastres tras desastres. Queremos algo no tan trágico, menos amarillistas. (Estudiante de 23 años, Barrancabermeja, 17 de junio de 2017).

Como se ha mencionado, el hábito del consumo de televisión se concentra en noticieros, formato que fomenta el debate político en la familia. Afirman que existen momentos diferentes del día o la semana para discutir o conversar 
en su grupo familiar sobre hechos políticos. Por eso, aunque aseveran que en muchas ocasiones son los medios masivos tradicionales los más provocadores en las conversaciones en lo político, las redes sociales son las que permiten mayor información e inmediatez sobre los temas en discusión, en particular Twitter, la cual denominaron como la red social donde mayor contenido político circula, debido a su cualidad de flujo informativo recíproco y constante.

Tenemos, al respecto, manifestaciones como las siguientes: “[...]EI noticiero es el detonante para que exista el debate en la mesa” (Entrevista 7, 24 años, Bucaramanga, 10 de junio de 2017). O, "la verdad las conversaciones en lo político inician con los noticieros, las noticias que son coyunturas, nacionales y los temas que están en el auge político de Colombia” (Estudiante de 21 años de Bucaramanga, 10 de junio de 2017).

De igual forma, hay comentarios como este: "Twitter es la red social que permite desligar al periodista del medio y es propia voz, rompe con la institucionalidad, nos exige condensar, Twitter va a lo que va, la censura es muy poca, es difícil encontrar un contenido real. (Estudiante de 21 años de Bucaramanga, 10 de junio de 2017).

Y otro de los jóvenes entrevistados manifestó:

Del contenido político, en Twitter, yo estoy muy cerca por las personas a las que sigo, esto es lo que pasa, que esta red es muy selectiva. Si tú sigues a esos amigos que publican una foto en el baño vas a tener contenido de ese tema. (Estudiante de 23 años de Bucaramanga, 10 de junio de 2017).

De la información sobre temas políticos que reciben a través de las redes sociales, aseguran que siguen lo relacionado con candidatos a elección popular, líderes políticos, temas de corrupción y situaciones locales.

El estudio permitió evidenciar los múltiples canales o medios por los que los jóvenes reciben información, al igual que las diferentes maneras como les presentan los contenidos. Los resultados permiten establecer que, además de los medios masivos tradicionales, diversas plataformas digitales entregan múltiples mensajes sobre actualidad general, estos discursos son presentados de manera dinámica y en tiempo real.

Los jóvenes señalaron nuevas narrativas y formatos como una forma novedosa de generar contenidos en la $W e b$, tales como infografías, memes, 
fotos, caricaturas, vídeos animados, gif, transmisiones en vivo, carteles o frases contundentes y dosis de humor como los elementos que les atraen y siguen.

Acontece que uno averigua qué ha pasado, se informa, sigue bajando en Facebook, se encuentra el meme, se ríe, lo guarda, lo manda por WhatsApp, las personas te contestan con otro meme y así solo fueron cinco minutos de información, y el resto, una hora de ocio y hasta más. (Estudiante de 20 años de Ocaña, 1 de julio de 2017).

De otro lado,

Los más frecuentes, por ahora, vienen siendo los memes que están muy de moda, ya que aprovechan cada equivocación, cada acierto, cada desliz de cada político para su diseño. Lo otro son las transmisiones en vivo que hoy en día están muy en la vanguardia, porque es muy fácil de hacer llegar a las demás personas y ya es una herramienta bastante usada por cada candidato y personaje político nacional. (Estudiante de 20 años de Bucaramanga, 10 de junio de 2017).

\section{Condicionantes sociales y procesos de participación política y electoral}

En relación con las condicionantes sociales que intervienen los procesos de participación política y electoral de los jóvenes, la indagación dejó claro que el tema político no es ajeno a su vida diaria, no obstante, no es una prioridad. Sin embargo, aceptan que la actividad política tiene diferentes miradas y formas de lograrse, una de ellas es la interacción virtual; aunque no es la única, consideran que no es totalmente eficaz para estos fines.

Yo considero que las redes sociales sirven para muchísimas cosas, si vamos a ver la historia, desde el 2000 en adelante la gente se ha vinculado más y se han logrado acontecimientos como la Primavera Árabe, que revolucionó casi un continente completo. Cosas como esas son para mí evidencia de que puedes compartir tu opinión con más personas, generando problemas, algunas veces, claro está, pero si son bien utilizadas, aparte de estar informados, nos generan muchas otras cosas (Estudiante de 22 años de Ocaña, 1 de julio de 2017). 
Otra de las personas que hicieron parte del estudio expresó:

Me interesa mucho, yo pienso que no hay un afuera de lo político, entonces todo lo que vez se vuelve interesante por los ejercicios de poder, y como desde ese poder se puede modificar la realidad desde esas relaciones de poder, esta idea es una influencia. (Estudiante de 20 años de Bucaramanga, 10 de junio de 2017).

La familia es un condicionante en temas políticos, en este sentido, los jóvenes dijeron hablar con sus padres sobre la actualidad política y reconocieron haber hecho públicas ante ellos sus diferencias ideológicas.

Al respecto, tenemos las siguientes dos intervenciones adicionales:

Mi familia incide en mi decisión de voto, porque la familia es la que lo forma a uno como persona. Por ejemplo, mi postura depende directamente de mi familia y eso es lo que se ha visto reflejado en la historia, hijo de papá conservador votaba conservador. En sí la forma de mi pensar y actuar depende de mi familia, más que amigos es mi familia. (Estudiante de 20 años de Ocaña, 1 de julio de 2017).

En mi caso específico es mi papá el que envía cadenas de WhatsApp, me manda audios de la situación de Venezuela y todo eso, entonces yo ahí me pregunto por el sentido común de las cadenas de WhatsApp, es curiosa la alteración de los contenidos que circulan en las redes sociales. (Estudiante de 23 años de Bucaramanga, 22 de julio de 2017).

Los momentos de mayor relación con la familia y donde se presenta la oportunidad para dialogar sobre diversos temas, entre ellos, la política, son las comidas; y las personas que normalmente ponen el tema son los padres, les siguen la televisión y los mismos jóvenes: "Mi actitud cuando hablo con mis padres de política es activa, polémica, contestataria, el debate siempre pone las cosas difíciles en la mesa", comenta una de las personas entrevistadas. "Mi actitud es arrogante, no estoy de acuerdo con ninguno”, opina otro de los encuestados.

Los resultados dejaron evidenciar que otro(s) actores diferentes a la familia les permiten a los jóvenes construir criterios, aceptar diferencias y consentir postulaciones o recomendaciones al momento de votar. Los amigos, la pareja sentimental y profesores son quienes ellos reconocen como influenciadores en sus decisiones políticas. 
Yo pienso que en mi decisión de voto incide todo, mis profesores de la universidad son los primeros por la opinión, alguien de rango intelectual, lo académico yo confió en eso, mi familia nunca ha influido en mi posición. (Estudiante de 20 años de Bucaramanga de 22 de julio de 2017).

Además,

Todas, porque primero los amigos o alguien que podría estar trabajando en la campaña política de uno de ellos y también en las redes sociales publican mucho, 'por esto, por esto, vote por esto, haga esto' y lo otro son amigos y personas independiente que no sean de la familia, ofrecen cosas para la votación. (Estudiante de 20 años de Bucaramanga, 22 de julio de 2017).

Y,

Yo hablo más con los amigos, hablo más sobre la política, porque ya hay más diversidad, un pensamiento e ideología más parecidos a uno (Entrevista 27, 18 años). Hablo más sobre política con mi pareja, porque la confianza que hay con ella para tocar esos temas. (Estudiante de 24 años de San Gil, 3 de junio de 2017).

Los jóvenes del oriente colombiano expresaron que los comentarios en redes sociales remitidos por amigos tienen impacto y es muy probable que los compartan y comenten, inclusive, aceptaron que avalan las ideas y corrientes ideológicas provenientes de su círculo de compañeros cercanos.

Pese a lo expuesto anteriormente, los jóvenes toman posiciones difusas frente a reconocer o aceptar la existencia de un tercero (personas) o medio (redes sociales o medios masivos) que incidan de manera directa en su decisión de voto 0 , en general, en temas políticos. En este ámbito, también cuestionaron y reprocharon a amigos y familiares que toman posiciones y siguen a personajes de la vida política colombiana más por imágenes, frases 0 videos, muchos de ellos atendiendo a noticias falsas, más que por ideas y argumentos. De esta situación hacen responsables a la televisión y a las redes sociales.

Yo creo que si hay un país que no vota por propuestas, sino por caras es Colombia. Las personas dicen: voy a votar por que tiene las mejores propuestas; uno pregunta: cuáles son las propuestas y no saben responder porque en realidad no han leído los programas. Yo no me dejaría influenciar 
mucho por redes sociales porque sé cómo se maneja el marketing estos aspectos. (Estudiante de 23 años de Cúcuta, 27 de marzo de 2017).

Además,

A mí me parece que los medios ejercen una influencia, es determinante la opinión que tiene un medio, cada uno tiene una línea editorial y la opinión de cada seguidor y eso es lo que a mí me gusta muchísimo ver, yo a veces consulto a El Tiempo o a Portafolio, cada una de esas personas tiene una forma de pensar, me gusta Facebook, que uno puede ver los comentarios, el criterio es válido y eso ejerce mucho en la opinión, mi criterio es muy influenciado por los medios. (Estudiante de 23 años de Bucaramanga, 21 de julio de 2017).

\section{Conclusiones}

Para los jóvenes del oriente colombiano es una constante, convertida en hábito, revisar las redes sociales. Las franjas de mayor consumo de estos espacios son la mañana (de 7:00 a.m. a 9:00 a.m.), sigue la tarde (de 3:00 p.m. a 6:00 p.m.) y en la noche esta práctica vuelve a incrementarse (de 10:00 p.m. a 1:00 a.m.).

Facebook, Instagram y Twitter son las tres redes sociales más utilizadas por los jóvenes. Twitter es, para ellos, una red con prevalencia de contenido político, y para actividades de tipo social prefieren Facebook.

Asumen Twitter como un espacio donde se expresan opiniones que no hacen públicas en otros escenarios reales o virtuales, sin embargo, su uso es menor en comparación con las otras redes sociales, y esto lo justifican en el límite de caracteres para escribir.

Noticias, fotos, videos, publicidad, espectáculos y política representan los mayores contenidos que leen; además comparten humor, novedades de farándula, lugares, gif, y memes, particularmente los de contenido político. La menor actividad que realizan es comentar; manifiestan que tienen posiciones sobre diversos temas, incluida la política, pero saben que en escenarios virtuales están propensos a ser cuestionados o, en su defecto, ser objeto de burlas o de insultos por parte de propios y extraños, situación que no les 
interesa experimentar. También reconocen que, en ocasiones, y por situaciones en las que se ven comprometidos, exponen y defienden sus planteamientos.

Por lo tanto, sus ideas, valores, creencias y percepciones en lo político desde lo virtual son limitadas, mientras que, en escenarios reales son más abiertos, en particular, en con sus pares o familiares.

Los jóvenes consideran que la familia es un grupo social especial para recibir información y orientación. Aunque no es contundente asegurar que en ella se consolidan principios de participación política y electoral, aun así, es percibida como un espacio que reconocen como propicio para la reflexión.

En este sentido, se agrega que los jóvenes que viven en un hogar con posibilidades de dialogar sobre temas políticos, donde los padres aceptan 0 rechazan posiciones contrarias de sus hijos, pero las respetan, hace posible que el joven, como ciudadano, se vea interesado por lo que ocurre en su contexto político y electoral. En síntesis, la existencia de un integrante de la familia que en su cotidianidad favorezca la discusión sobre la participación política y electoral, alimentará o motivará a ese joven a preguntar, a cuestionarse y a indagar con otros sobre este tipo de temáticas, y esto impulsa lo que Price (1994) denominó público atento y activo.

Aunque no era parte primordial del estudio, se debe registrar la novedad del ingreso de WhatsApp a la rutina de los jóvenes y, en particular, a la familia. Se evidenció que la llegada de esta aplicación y su uso permanente produjo cambios en las prácticas comunicativas de los integrantes, convirtiéndose en el medio de mayor interacción entre sus miembros. Por una cuenta de WhatsApp familiar circulan mensajes de motivación, cadenas de oración, fotos antiguas, invitaciones a reuniones sociales, saludos de cumpleaños, discursos de candidatos, venta de productos y memes políticos, lo que altera de manera favorable y desfavorable a los integrantes.

La población con la cual se trabajó en este proyecto, perfilada como nativos digitales, dice sentirse invadida por los inmigrantes digitales (padres, tíos, abuelos y demás familiares mayores); insinúan que su "privacidad virtual" se perdió, pues otras generaciones han incursionado y participan en ella. La situación es tal, que algunos manifestaron haber migrado a redes sociales menos concurridas o más complejas en su uso, con el fin de mantener su privacidad en las publicaciones que realizan, en tanto les generan reafirmación de su propia identidad. 
Los jóvenes son conscientes de su realidad social, de su compromiso con las decisiones que les corresponden y reconocen que la sociedad en general no los considera competentes, ni les otorgan posibilidades para demostrar lo contrario. También aceptan que la conducta general atiende a la apatía apáticos, no solo en lo político y electoral, sino en otros temas, pero no se consideran distantes o desinteresados. No obstante, se reconocen diferencias entre los jóvenes provenientes de diferentes ciudades, así, por ejemplo, existe un perfil mucho más participativo de los jóvenes procedentes de Barrancabermeja y con una preocupación acentuada en aspectos de tipo social y político; por su parte, se observó una condición de desinterés y apatía en estos temas en las personas provenientes de Bucaramanga.

De lo anterior se colige que existe un modelo multi-comunicacional y dinámico en la medida en que los jóvenes reciben información a través de redes sociales, medios masivos y sus círculos de relación cercanos, que condicionan su participación política. Esta última se observa aún pasiva y se requiere que sea determinante para los procesos decisorios del país, aspecto que implica esfuerzos ingentes por fortalecer los contenidos y la creatividad en las narrativas utilizadas y los contenidos desarrollados.

\section{Referencias}

Botero \& Torres, J. (2008). Perspectivas teóricas para comprender la categoría participación ciudadana-política juvenil en Colombia. Revista Latinoamericana de Ciencias Sociales, Niñez y Juventud 6 (2), pp. 565-611. Recuperado de: http:// www.umanizales.edu.co/revistacinde/index.htm

Caldevilla Domínguez, D. (2009). Democracia 2.0: la política se introduce en las redes sociales. Pensar la Publicidad, III (2), 31-48.

Cambell, D., \& Stanley, J. (1966). Experimental and Quasi Experimental Design for Research. Dallas: U.S.A.

Castillo Cubillos, M. (2017). El papel de la participación ciudadana en las políticas públicas, bajo el actual escenario de la gobernanza: reflexiones teóricas. Revista CS, (23), pp. 157-180.

Departamento Nacional de Estadística. Dane. (2017). Encuesta sobre cultura política. http://www.dane.gov.co/files/investigaciones/ecpolitica/Form_ECP_13_10_14.pdf 
Escobar, M. (2009). Jóvenes: cuerpos, significados, sujetos estudiados. Nómadas (30), pp. 104 - 117. Recuperado de http://www.redalyc.org/articulo.oa?id=105112060009>

García Canclini., N. (2009). El consumo cultural: una propuesta teórica. En G. Sunkel. El consumo cultural de América Latina. (26-49). Bogotá:

Losada y Casas, A. (2010). Enfoques para el análisis político. Historia, epistemología y perspectivas de la ciencia política. Bogotá: Editorial Pontificia Universidad Javeriana.

Martín-Barbero, J. (1988). "Jóvenes: des-orden cultural y palimpsestos de identidad", en Cubides, H. y otros, (editores): "Viviendo a toda» Jóvenes, territorios culturales y nuevas sensibilidades. Bogotá: Siglo del Hombre-Universidad Central.

Mantecón, A. (2008). Consumos culturales: públicos, mercados y políticas. Alteridades, 18 (36): Pp. 23, 31. Recuperado de: https://alteridades.izt.uam.mx/index.php/Alte/ article/view/195/194

Ministerio de las TIC (2015). Uso y Apropiación de las TIC en Colombia. República de Colombia. Ministerio de Tecnologías de la Información y Comunicación. Recuperado de https://www.mintic.gov.co/portal/604/articles-15296_recurso_3.pdf

(2017). Boletín trimestral de las TIC, julio 2017. República de Colombia, Ministerio de Tecnologías de la Información y Comunicación. Recuperado de http:// colombiatic.mintic.gov.co/602/articles-55212_archivo_pdf.pdf

. Primera gran encuesta TIC/2017. Estudio de acceso, usos y retos de las TIC en Colombia. República de Colombia. Ministerio de Tecnologías de la Información y Comunicación. Recuperado de http://colombiatic.mintic.gov.co/602/w3article-57508.html

Misión de Observación Electoral MOE. (2011). Encuesta: Percepción electoral de los votantes colombianos. Recuperado de: http://moe.org.co/home/ doc/encuesta/ encuestamoe.pdf.

Moreno. M. (2017). Facebook ya tiene 1.860 millones de usuarios. En TreceBits redes sociales y periodismo. Blog. Recuperado de http://www.trecebits.com/2017/02/02/ facebook-ya-tiene-1-860-millones-de-usuarios/

Pérez, J. (1998). Jóvenes. Sujetos, trayectorias y ciudadanías. México: Universidad Nacional Autónoma de México. Recuperado de: https://www.academia.edu/19244676/ J\%C3\%B3venes._Sujetos_Trayectorias_y_Ciudadan\%C3\%ADas

Quintero Tobón, F. (2005). Dejóvenes y juventud. Nómadas (23), pp. 94 - 102 Recuperado de http://www.redalyc.org/articulo.oa?id=105116741011 > ISSN 0121-7550 
Registraduría Nacional del Estado Civil. (2014). Comunicado de prensa No.0085 de 2014. Recuperada de < http.//wsr.registraduria.gov.co/1-550-600-santandereanosestan.html., wsr.registraduria.gov.co/IMG/pdf/censo.pdf>

Reguillo, R. (2000). Emergencias de culturas juveniles. Enciclopedia latinoamericana de sociocultura y comunicación. Bogotá: Editorial Norma.

Rivera, J. (2013) Ciudadanías y culturas políticas entre las juventudes mexicanas. En: Devenir ,Revista de Estudios Culturales y Regionales (24). Recuperado de: https:// www.academia.edu/7694069/REVISTA_DEVENIR._NUMERO_ESPECIAL_SOBRE_ LOS_JOVENES

SEO Colombia. (2012). Estadísticas de Facebook en Colombia. En blog. Recuperado de https://www.seocolombia.com/blog/estadisticas-facebook-colombia-2012/

Valenzuela, J. (2009). El futuro ya se fue. Socioantropología de l@s jóvenes en la modernidad. México: Colegio de la Frontera Norte. 